\title{
REACTIONS TO THE PANDEMIC IN BRAZIL: PREDICTORS OF MENTAL HEALTH AND LIFE SATISFACTION
}

\author{
Mayra Antonelli-Ponti*, Scheila Farias de Paiva1,2, Cláudia Helena Cerqueira Mármora ${ }^{2,3}$, \\ Sandra Bastos ${ }^{4}$, Juliana Almeida da Silva ${ }^{5,6}$, Luis Antonio Monteiro Campos 7,8 , Alberto Abad1, \\ Lucas Emmanuel Pedro de Paiva Teixeira ${ }^{9}$, José Aparecido da Silva10
}

${ }^{1}$ Psychology Graduate Program, Federal University of Juiz de Fora (UFJF), Juiz de Fora, Brazil; ${ }^{2}$ Speech Therapy of Federal University of Sergipe (UFS), Lagarto, Brazil; ${ }^{3}$ Department of the Old, Adult, and Maternal-Infant, School of Physical Therapy, Federal University of Juiz de Fora (UFJF), Juiz de Fora, Brazil; ${ }^{4}$ Otorhinolaryngology Institute (ISBO), São Paulo, Brazil; 5Laboratory of Neuroanatomy and Neuropsychobiology, Department of Pharmacology, Ribeirão Preto Medical School of the University of São Paulo (FMRP-USP), Brazil; ${ }^{6}$ Behavioural Neurosciences Institute (INeC), Ribeirão Preto, Brazil; ${ }^{7}$ Department of Psychology, Pontifical Catholic University of Rio de Janeiro, Rio de Janeiro, Brazil; ${ }^{8}$ Master's Program in Psychology, Catholic University of Petrópolis, Petrópolis, Brazil; ${ }^{9}$ Institute of Motricity Sciences, Federal University of Alfenas (UNIFAL-MG), Alfenas, Brazil; ${ }^{11 B i o m e d i c a l ~ S c i e n c e s ~ I n s t i t u t e, ~}$ Federal University of Alfenas (UNIFAL), Minas Gerais, Brazil; ${ }^{10}$ Laboratory of Psychophysics, Perception, Psychometrics, and Pain, the University of São Paulo at Ribeirão Preto, Brazil

\section{ARTICLE INFO}

Article History:

Received $10^{\text {th }}$ October, 2020

Received in revised form

$20^{\text {th }}$ November, 2020

Accepted $18^{\text {th }}$ December, 2020

Published online $30^{\text {th }}$ January, 2021

Key Words:

Psychological distress, generalized anxiety, depression, life satisfaction, pandemic context.

*Corresponding author: Mayra Antonelli-Ponti

\begin{abstract}
The present study investigates mental health indicators: depression, anxiety, stress, sadness, satisfaction with life and associated variables, gender, educational level, having an academic or professional occupation, the constancy of physical exercises, presence of chronic disease, displaying symptoms, having been infected, having tested for Covid-19, isolation level, working from home, searching for information related to Covid-19, time devoted to social networks and belief in infection by Covid-19 from you and others. A cross-sectional survey was conducted from May 9th to July 2nd of 2020. The sample was recruited $(n=862)$ to participate using an online spreadsheet (Google forms) circulated on social media, television, and e-mails. Sociodemographic questionnaires and scales to measure mental health aspects were applied. The mental health indicators are negatively correlated with life satisfaction. Being a woman and being younger predict higher levels of mental suffering. We have presented other predictors of mental health and life satisfaction during the pandemic. The lack of control generated by the pandemic itself, and aggravated by the circumstances in Brazil -increasing infection and deaths- shows a clear relationship with psychological distress. From the results offered by the present research, there is no single solution or "magic answer" to alleviate the psychological suffering of the Brazilian people.
\end{abstract}

Copyright (C) 2021, Mayra Antonelli-Ponti, Scheila Farias de Paiva, Cláudia Helena Cerqueira Mármora, Sandra Bastos, Juliana Almeida da Silva, Luis Antonio Monteiro Campos, Alberto Abad, Lucas Emmanuel Pedro de Paiva Teixeira, José Aparecido da Silva. This is an open access article distributed under the Creative Commons Attribution License, which permits unrestricted use, distribution, and reproduction in any medium, provided the original work is properly cited.

Citation: Antonelli-Ponti, M., de Paiva, S. F., Mármora, C. H., Bastos, S., da Silva, J., Campos, L. A. M., Abad, A. de Paiva Teixeira, L. E. P., da Silva, $\boldsymbol{J}$. A, 2021. "Reactions to the pandemic in Brazil: predictors of mental health and life satisfaction" International Journal of Development Research, 11, (01), $43562-43566$

\section{INTRODUCTION}

The year 2020 was marked by the pandemic caused by the new coronavirus, with many challenges, uncertainties, doubts, and psychological suffering emerging at an alarming level in Brazil and other countries with similar coping policies, levels which are especially great when compared to countries with more efficient coping strategies (Antonelli-Ponti et al., 2020). Lima (2020) discusses the Brazilian reality, where there are people in total isolation, living alone and afraid of infection; people who need to travel, work and guarantee their livelihood, living under the constant fear of starving and, or becoming homeless and who are therefore unable to adopt the measures recommended by the authorities. Adherence to behavior patterns that prevent the spread of the virus, such as isolation and social detachment, has implications predicted and described by Taylor (2019). These factors added to the fear of infection (Abad et al., 2020) 
and social insecurity (Antonelli- Ponti et al., 2020), causing damage to the mental health of people in different places on the planet (Abad et al., 2020; Antonelli -Ponti et al., 2020; González-Sanguino, et al., 2020; Moccia et al., 2020; Yamamoto et al. 2020; Yu et al., 2020) and in different social groups (Kang et al., 2020). In addition to the differences between countries and even between states, it is known that people's characteristics and previous conditions can influence the way they deal with the current context. Abad et al. (2020) demonstrate the difference between genders, with women being more afraid of Covid-19 and more levels of peritraumatic distress than men. Other differences in anxiety, exhaustion, and attention deficit were also revealed, thus demonstrating that people with chronic illnesses such as diabetes, cardiovascular diseases or with previous psychological suffering also have higher levels of fear and peritraumatic distress compared to those who did not report such conditions (de Paiva Teixeira et al., 2020).

Due to a handful of factors, people have experienced and continue to experience pandemic surges in different fashion. We know that there may be different reactions, varying from each individual, as well as different psychological stressors, such as fear, indifference, fatalism, anxiety, depression, among others. Some people may be so anxious that they experience significant levels of clinical stress, avoidance, and functional impairment, reaching a level of behavior so high that they begin to demand specific treatment for their emotional disorder. Studies suggest that life satisfaction assessments are a reliable indicator, providing a good sense of individuals' subjective well-being (BES), being a relevant construct in the context of life during the pandemic in several countries (Bedin and Sarriera, 2014; Diener, 2012). The present study investigates mental health indicators: depression, anxiety, stress, sadness, contentment with life and other associated variables such as sex, level of education, occupation, the constancy of physical exercise, presence of chronic disease, presence of symptoms, having already been infected, having been tested for Covid-19, isolation level, working from home, looking for information related to Covid-19, time devoted to social media and belief in the possibility that both you or others may be infected by Covid-19. Considering psychological factors as being health indicators of the Brazilian population, one of this study's objectives was to measure psychological distress, generalized anxiety, depression, and the overall satisfaction with life, both in the beginning, and in the middle of the period of isolation and social distancing brought on by Covid-19.

\section{METHODS}

This is a cross-sectional survey design and refers to the second module of the research project entitled "Physical, psychological and cognitive reactions to Covid-19" with data collected from May 9 to July 2, 2020, and approved by the Ethics Committee.

Participants : It is a non-probabilistic sample composed of 862 people distributed in different regions of Brazil, who were recruited by an online spreadsheet (Google forms), which was disseminated on social networks, television, and by email as an information collection tool. Before responding to the questionnaire, candidates read and accepted the Participant's Consent Form, which explains the purpose of this study, offers a guarantee that it can be interrupted as soon as the participant no longer wishes to continue, and guarantees the anonymity of their responses.

Research tool: The online spreadsheet used to set up the survey consists of a six-part questionnaire, split into specific topics which encompass: a sociodemographic survey that included detailed questions about the prevalence of chronic diseases and levels of social isolation during the Covid-19 pandemic; the adapted Kessler psychological stress scale, dubbed "K5"; the Patient Health Questionnaire-9 (PHQ-9); Generalized Anxiety Disorder (GAD-7); Non-Somatic Pain Scale (NSP); and the Satisfaction With Life Scale during the Covid-19 pandemic (SWLS).
Demographic data: Primary demographic data includes place of residence (State of Brazil), occupation (doctor or nurse), sex (male or female), age (years), education (from elementary school to graduate school), occupation (study or work).

Physical Health and Covid-19: Participants were asked if they had a chronic illness, if they had any Covid-19 symptoms, if they had been tested for Covid-19, and if they had been infected with Covid-19, and were directed to answer all of these questions with YES or NO.

Routine during Pandemic: During the pandemic, daily routine was determined by the level of isolation (partial or total), the time spent working at home per day, the time spent exercising, time dedicated to cell phones, social networks, and the search for information about Covid-19.

Belief in Covid-19 Infection: Participants indicated their answer using a scale ranging from zero to ten on how likely they believed a infection of themselves, of a member of their family, or a colleague's by Covid-19 was.

Mental Health and Life Satisfaction: These psychometric scales were prepared in the form of a self-report questionnaire and presented in the Likert format in different responses. These surveys are of brief application and have already been adapted to Brazilian Portuguese, with authorization from the authors, and have been employed in research and widely adopted for diagnostic screening of mental disorders.

The patient's Health scale (PHQ-9) (Choi et al., 2020) The instrument consists of nine questions that assess: depression, anhedonia (loss of interest or pleasure in doing things), problems with sleep, tiredness or lack of energy, change in appetite or weight, feeling of guilt or worthlessness, problems concentrating, feeling slow or restless and thoughts of suicide. One of its advantages is that the PHQ-9 can be both self-applied and applied by trained interviewers. Its organization is a Likert scale organized from 0 to 3 corresponding to 0 - "no time," 1- "several days," 2 - "more than half the days," and 3 - "almost every day," respectively. The generalized anxiety scale (GAD-7) (Choi et al., 2020). The instrument consists of seven statements about feelings of anxiety arranged on a four-point plate with 0 (note once) to 3 (almost every day). The score ranges from 0 to 21 when measuring the frequency of signs and anxiety symptoms in the past two weeks. A positive indicator of signs and symptoms of anxiety disorders is considered a value equal to or greater than 10 . The Kessler psychological distress scale (K5) (Kessler et al, 2002a, 2002b). An instrument is a brief tool for assessing, diagnosing, and monitoring psychological stress. It was devised with five statements related to the amount of pressure one was under, with response options ranging from (1) none to (5) almost every day. The K6 scale with five statements (K5) was used, with the item "Do you feel so depressed that nothing can cheer you up?" having been removed, considering that the surveys form already contained the depression scale (PHQ-9). It is noteworthy that this item presented factorial load null in a recent study (Easton et al, 2017). The non-somatic pain scale (NSP) (da Silva, Ribeiro-Filho, 2011). The instrument contains three statements related to the occurrence of non-physical pain, like agony and sadness. The response options range from (1) never, rarely to (4) always. The Satisfaction With Life Scale (SWLS) (Diener et al., 1985). The instrument is a self-report questionnaire that includes five statements to measure overall satisfaction with life among various subjective well-being components. It focuses on overall satisfaction with liferelated to how people perceive their lives and feel satisfied. Its psychometric properties prove to be favorable, including high internal consistency and high temporal reliability. Scores correlate from moderately to highly with other measures of subjective well-being and predictably correlate with specific personality characteristics. Response options range from (1) strongly disagree to (7) strongly agree. The scales show high internal consistency, as measured by Cronbach's alpha: PHQ-9 $=0.828$; GAD-7 $=0.931$; K5 $=0.828$; NSP $=0.843 ;$ SWLS $=0.890$. 
Data analysis: Data analysis was performed using IBM SPSS Statistics for Windows (Version 23.0). Descriptive analysis was used to report the general data, Pearson's correlations, and conducted multiple regression analyses. The possible multicollinearity between the variables of interest was examined, ensuring that the variance inflation factor (VIF) indicator obtained from the linear regression analysis was $<3.4$. We calculated the clinical results (scores) of PHQ9, GAD-7, and K5 by adding each individual's responses to the full scale.

\section{RESULTS}

Demographic variables: The data gathered from eight hundred sixty two Brazilians $(\mathrm{n}=862)$. The average age is $35.5(\mathrm{SD}=13.1)$. Most of the sample is female $(74.4 \%)$, possesses a higher education $(71.1 \%)$, and $(90.3 \%)$ have a job or occupation. Three of the federative units in Brazil are more greatly represented here: $34 \%$ of respondents live in Sergipe, in the northeast region, 20.5\% live in São Paulo, and 19.3\% live in Minas Gerais, both of these located in the southeast of Brazil; $25.9 \%$ of respondents live in the other 21 federative of Brazil (Table $1)$.

Table 1. Frequency of sociodemographic variables

\begin{tabular}{llcc}
\hline \multicolumn{1}{c}{ Variable } & & $\mathbf{n}$ & $\mathbf{\%}$ \\
\hline \multirow{3}{*}{ Sex } & Male & 221 & 25.6 \\
& Female & 641 & 74.4 \\
& & & \\
\multirow{2}{*}{ Educational level } & Complete elementary school & 11 & 1.3 \\
& Complete middle school & 238 & 27.6 \\
& Complete college & 332 & 38.5 \\
& Complete post-graduate studies & 281 & 32.6 \\
& Autonomous & & \\
& Employed & 167 & 19.4 \\
& Student & 382 & 44.3 \\
& Unemployed & 229 & 26.6 \\
& Retired & 50 & 5.8 \\
& & 34 & 3.9 \\
& SE (Sergipe) & & \\
& SP (São Paulo) & 293 & 34 \\
& MG (Minas Gerais) & 177 & 20.5 \\
& other states & 166 & 19.3 \\
& other countries & 224 & 25.9 \\
& & 2 & 0.3 \\
\hline
\end{tabular}

Table 2. Descriptive statistics of the scales

\begin{tabular}{llllc}
\hline & Minimum & Maximum & Average & SD \\
\hline K5 & 1 & 5 & 2.25 & 0.80 \\
score: K5 & 5 & 25 & 11.26 & 3.98 \\
PHQ-9 & 0 & 3 & 1.07 & 0.68 \\
score: PHQ9 & 0 & 27 & 9.66 & 6.15 \\
GAD7 & 0 & 3 & 1.24 & 0.86 \\
score: GAD7 & 0 & 21 & 8.68 & 5.97 \\
SWLS & 1 & 7 & 4.65 & 1.39 \\
NSP & 1 & 4 & 1.78 & 0.72 \\
\hline
\end{tabular}

Table 3. Correlations matrix among scales

\begin{tabular}{lcccc}
\hline & PHQ9 & GAD7 & SWLS & NSP \\
\hline K5 & $.76^{* *}$ & $.74^{* *}$ & $-.28^{* *}$ & $.65^{* *}$ \\
PHQ9 & & $.78^{* *}$ & $-.32^{* *}$ & $.70^{* *}$ \\
GAD7 & & & $-.26^{* *}$ & $.73^{* *}$ \\
SWLS & & & & $-.32^{* *}$ \\
\hline
\end{tabular}

Physical health and Covid-19: About the physical variables, most of the sample does not have a chronic disease $(75.8 \%)$; $(81.9 \%)$ declared to not have any symptom of Covid- $19,(95.8 \%)$ claim not to have been tested for Covid-19, (98.3\%) claim that they did not have Covid-19.

Routine during Pandemic: The level of isolation was measured through two questions about how many times the participant goes out in a week $\mathrm{M}=1.76 \mathrm{DP}=3,14(\mathrm{n}=860)$ and in one day $\mathrm{M}=1.79$ $\mathrm{DP}=1.96(\mathrm{n}=824)$. The participants in this sample declared who declared to have worked from home for more than four hours per day $(\mathrm{n}=846 ; \mathrm{M}=4.33 \mathrm{DP}=4.07)$; had used their cell phone for more than eight hours per day $(\mathrm{n}=794 ; \mathrm{M}=8.36 \mathrm{DP}=4.40)$; had accessed social media for more than five hours per day $(n=805 ; M=5.49 \mathrm{DP}=4.24)$; searched for information about Covid's for more than one hour per day $(\mathrm{n}=805 ; \mathrm{M}=1.39 \mathrm{DP}=1.39)$ and had exercised one hour per day $(\mathrm{n}=862 ; \mathrm{M}=1.05 \mathrm{DP}=1.49)$.

Belief in Covid-19 Infection: When asked how much they believed that they, their family, and colleagues could be infected with covid-19, on a zero to 10 scale, the average answer was $6.02(\mathrm{SD}=2.9), 6.6$ $(\mathrm{SD}=2.8)$, and $7.45(\mathrm{SD}=2.5)$, respectively.

Mental health: The Patient Health Questionnaire-9 (PHQ-9) showed a total score ranging from zero to 27 , with a higher score indicating more significant self-reported depression. A total score equal to or greater than 10 indicated a possible major depression, using the same parameter as Choi et al. (2020). The score indicating major depression appeared in $45.9 \%$ of the sample. The Generalized Anxiety Disorder (GAD-7) showed a total score ranging from zero to 21 , with higher scores indicating more significant self-reported anxiety. A total score of 10 or more indicated a possible feeling of strain, using the same parameter as Choi et al. (2020). The score suggests feelings of anxiety present in $40.7 \%$ of the sample. Kessler's psychological stress scale (K5) showed a total score ranging from 5 to 25 , with a higher score indicating more significant self-reported psychological stress (Staples et al., 2019). As the average score was 11.26 , a score above 12 pointed to a feeling of psychological stress, which occurred in $41.5 \%$ of the sample. The following table shows the averages of all scales (Table 2).

Correlation: The average score of the scales was used to correlate the rankings with each other. There was a positive and robust correlation among K5, GAD7, PHQ9, and NSP, indicating that these feelings (depression, stress, anxiety, non-somatic pain) increase together. The SWLS correlated negatively with PHQ9, GAD7, K5, and NSP, meaning that life satisfaction increases the less a person feels depression, stress, anxiety, and non-somatic pain (Table 3).

Differences between groups: Men $(n=221)$ and women $(n=641)$ showed some differences, as women always have higher levels of psychological stress [K5 (male $\mathrm{M}=2.07$; $\mathrm{SD}=0.79$ ); (female $\mathrm{M}=$ $2.32 ; \mathrm{SD}=0.79) ;(\mathrm{gl}=860 ; \mathrm{t}=-4.06 ; \mathrm{p}>0.001)]$; depression [PHQ-9 (male $\mathrm{M}=0.88 ; \mathrm{SD}=0.67)$; (female $\mathrm{M}=1.14 ; \mathrm{SD}=0.68) ;(\mathrm{gl}=860$; $\mathrm{t}=-5.051 ; \mathrm{p}>0.001)]$, generalized anxiety [GAD-7 (male $\mathrm{M}=1.03$; $\mathrm{SD}=0.88) ;($ female $\mathrm{M}=1.31 ; \mathrm{SD}=0.84) ;(\mathrm{gl}=860 ; \mathrm{t}=-4.368 ; \mathrm{p}>$ $0.001)]$ and non-somatic pain [NSP (male $\mathrm{M}=1.58 ; \mathrm{SD}=0.71)$; (female $\mathrm{M}=1.85 ; \mathrm{SD}=0.72) ;(\mathrm{gl}=860 ; \mathrm{t}=-4.787 ; \mathrm{p}>0.001)]$. Those people who were infected with Covid-19 $(\mathrm{n}=15)$ had higher levels than those who were not $(\mathrm{n}=847)$ in depression [PHQ-9 (infected $\mathrm{M}=1.65 ; \mathrm{SD}=0.74)$; (uninfected $\mathrm{M}=1.06 ; \mathrm{SD}=0.68) ;(\mathrm{gl}$ $=860 ; \mathrm{t}=3.322 ; \mathrm{p}>0.001)]$ and generalized anxiety [GAD-7 (infected $\mathrm{M}=1.69 ; \mathrm{SD}=0.74)$; (uninfected $\mathrm{M}=1.23 ; \mathrm{SD}=0.86)$; $(\mathrm{gl}$ $=860 ; \mathrm{t}=2.036 ; \mathrm{p}=0.04)]$. Those people who reported having chronic disease $(n=209)$ had lower levels of satisfaction with life (SWLS M $=4.43 ; \mathrm{SD}=1.36$ ), than those who declared they did not have chronic disease $(\mathrm{n}=653)$ [SWLS $(\mathrm{M}=4.43 ; \mathrm{SD}=1.36) ;(\mathrm{gl}=$ $860 ; \mathrm{t}=-2.528 ; \mathrm{p}=0.01)]$. When separated into two groups: those who had not gone out of their homes once a week $(n=563)$ and those who had gone out at least once $(n=297)$, those who were in complete isolation felt more depressed (PHQ-9 $\mathrm{M}=1.11 ; \mathrm{SD}=0.70$ ) and less satisfied with life (SWLS M $=4.58 ; \mathrm{SD}=1.40$ ) when compared to the other group [PHQ-9 $(\mathrm{M}=1.01 ; \mathrm{SD}=0.66) ;(\mathrm{gl}=858 ; \mathrm{t}=1.938 ; \mathrm{p}=$ $0.05)$; SWLS $(\mathrm{M}=4.78 ; \mathrm{SD}=1.37) ;(\mathrm{gl}=858 ; \mathrm{t}=-2.051 ; \mathrm{p}=0.04)]$.

Multiple linear regressions: Only the variables which correlated with the constructs of scales and those that showed differences between the groups in these scales were inserted in the predictor models of regression. The results are showed in Table 4. 
Table 4. Multiple linear regressions with predictors of mental health and life satisfaction during pandemic

\begin{tabular}{|c|c|c|c|c|c|c|c|c|c|c|}
\hline \multirow[t]{2}{*}{ Scales } & \multicolumn{2}{|l|}{ PHQ-9 } & \multicolumn{2}{|l|}{ GAD-7 } & \multicolumn{2}{|c|}{ NSP } & \multicolumn{2}{|l|}{ K5 } & \multicolumn{2}{|l|}{ SWLS } \\
\hline & B & $\mathrm{t}$ & B & $\mathrm{t}$ & B & $\mathrm{t}$ & B & $\mathrm{t}$ & B & $\mathrm{t}$ \\
\hline Constant & 0.766 & 4.832 & 2.038 & 4.32 & 1.603 & 9.394 & 2.04 & 10.962 & $3.434 *$ & 10.464 \\
\hline Sex & $0.236^{*}$ & 4.691 & $0.247 *$ & 3.894 & $0.226^{*}$ & 4.121 & $0.213 *$ & 3.566 & 0.001 & 0.339 \\
\hline Age & $-0.01 *$ & -6.392 & $-0.017 *$ & -6.863 & $-0.01 *$ & -4.539 & $-0.015^{*}$ & -6.482 & $0.34^{*}$ & 5.084 \\
\hline Educational level & -0.022 & -0.676 & -0.053 & -1.324 & $0.093^{*}$ & -2.712 & -0.065 & -1.74 & 0.077 & 0.987 \\
\hline Home office & $-0.014 *$ & -2.264 & - & - & - & - & - & - & - & - \\
\hline Physical exercises & $-0.04 *$ & -2.511 & $-0.047 *$ & -2.362 & - & - & - & - & - & - \\
\hline Social isolation & -0.048 & -1.311 & - & - & - & - & - & - & 0.077 & 0.987 \\
\hline Belief in Covid-19 Infection & $0.013^{*}$ & 1.036 & 0.017 & 1.107 & 0.012 & 0.935 & 0.007 & 0.479 & - & - \\
\hline Family & $0.028 *$ & 1.974 & 0.031 & 1.709 & 0.024 & 1.52 & $0.035^{*}$ & 2.095 & $-0.046^{*}$ & 2.616 \\
\hline Colleagues & 0.017 & 1.186 & 0.009 & 0.486 & 0.005 & 0.297 & 0.015 & 0.879 & - & - \\
\hline Time on phone & 0 & -0.036 & 0.006 & 0.818 & 0.002 & 0.221 & 0.011 & 1.47 & - & - \\
\hline Time on Social Media & $0.015^{*}$ & 2.159 & 0.012 & 1.399 & $0.016^{*}$ & 2.225 & 0.005 & 0.623 & $-0.033 *$ & 2.885 \\
\hline Time searching Covid-19 info & $0.043 *$ & 2.518 & $0.063 *$ & 2.951 & 0.032 & 1.764 & $0.052 *$ & 2.58 & - & - \\
\hline Infected by Covid-19 & - & - & $-0.495 *$ & -2.352 & - & - & - & - & - & - \\
\hline Chronic disease & - & - & - & - & - & - & - & - & $0.339 *$ & 3.052 \\
\hline
\end{tabular}

For $\mathrm{K} 5$, the model was valid $(\mathrm{F}=19.632 ; \mathrm{p}>0.001)$ and explained $19 \%\left(\mathrm{R}^{2}=0.19\right)$ of the variance of psychological stress reported by the sample. Being a woman, being younger, believing that someone in your family will become infected by Covid-19, and spending time looking for information about Covid-19 can predict higher levels of psychological stress. For the PHQ-9, the model was valid ( $F=18.772$; $\mathrm{p}>0.001)$ and explained $23 \%(\mathrm{R} 2=0.23)$ of the depression variance reported by the sample. Being a woman, younger, with fewer hours of work from home, fewer hours of exercise a day, believing that Covid19 will infect someone in your family, and spending time on social media and seeking information about Covid-19 can predict higher levels of depression. For GAD-7 the model was valid $(\mathrm{F}=18.303 ; \mathrm{p}>$ $0.001)$ and explained $20 \%\left(\mathrm{R}^{2}=0.20\right)$ of the generalized anxiety variance reported by the sample. Being a woman, younger, with fewer hours of exercise a day, spending time searching for information about Covid-19, and having been infected with Covid-19 can predict higher levels of generalized anxiety. For NSP, the model was valid $(\mathrm{F}=$ 14.964; $\mathrm{p}>0.001)$ and explained $15 \%\left(\mathrm{R}^{2}=0.15\right)$ of the non-somatic pain variance reported by the sample. Being a woman, younger, spending time browsing social networks, and having less education can predict higher non-somatic pain levels. For SWLS, the model was valid $(\mathrm{F}=11.498 ; \mathrm{p}>0.001)$ and explained less than $10 \%\left(\mathrm{R}^{2}=0.08\right)$ of the non-somatic pain variance reported by the sample. Believing in the possibility of infection of some family members by Covid-19, spending time on social media daily, homeschooling, and having a chronic disease can predict lower satisfaction levels with life. Was verified the multicollinearity and the values of VIF were among 1.0 and 3 .

\section{DISCUSSION}

During May 2020, more than $40 \%$ of this sample, composed of Brazilians, showed high levels of depression, generalized anxiety, and psychological stress. Depression, anxiety, stress, and sadness are strongly associated, while life satisfaction decreases as these indicators increase. Antonelli-Ponti et al. (2020) claims that Brazil's chaotic environment (already tumultuous even in the very beginning of the pandemic), generated higher levels of stress than in Portugal, for example. May was the month with more deaths by Covid-19 in the country (https://covid.saude.gov.br/); it was the moment in which Brazil started to experience the reality of losing about a thousand people a day due to Covid-19, therefore further aggravating the mental distress of the population. Levels of mental suffering presented in this study are high even when compared to studies that investigated health professionals from the first country to deal with the pandemic: the mental health of $30 \%$ of Chinese health professionals between January and February 2020 were at moderate levels to high, considering depression, anxiety, stress and insomnia (Kang et al., 2020). In addition, they are also elevated when compared to other countries with experiences of the initial uncontrolled pandemic, which were reported widely in Brazilian media. To further the comparison and highlight just how Brazilians are suffering at higher levels when compared to other populations around the world during the pandemic, in China, the first country that had to deal with Covid-19, in February $2020,22.8 \%$ of the sample showed moderate to highest levels of psychological distress (Yu et al., 2020). In Spain, in March 2020, $18.7 \%$ of the population had depression, $21.6 \%$ anxiety, and $15.8 \%$ post-traumatic stress (González-Sanguino et al., 2020). In Italy, in April of $2020,38 \%$ of a population sample had moderate to severe psychological stress levels (Moccia et al., 2020). In Japan, in May $2020,11.5 \%$ of the 11.333 investigated people were in psychological distress (Yamamoto et al., 2020). Women and younger people are in more significant mental suffering, with higher levels of depression, generalized anxiety, psychological stress, and sadness than men. Results corroborated by Brazil as well as other countries (Abad et al. 2020; González-Sanguino, et al., 2020). Abad et al (2020) emphasize that women take care of themselves and others and that, therefore, they tend to feel concerned for themselves and others, and therefore feel the effects of that extra uneasiness.

Several aspects can help understand the effect of the pandemic on the mental health of groups with different characteristics. Those who followed social isolation more strictly, as a behavioral measure to prevent infection, had a higher level of depression and less satisfaction with life than those who adopted more relaxed isolation practices, as Lima stated (2020). These people feel less satisfied with life than those who claim to have a chronic illness. Despite making up a small number $(\mathrm{n}=15)$, participants in this study infected with Covid19 showed more significant depression and anxiety than those who were not infected. More time on social networks predicted higher levels of depression, sadness, and a lower level of satisfaction with life. More time spent on searching for information about Covid-19 predicted higher levels of depression, anxiety, and psychological stress. It occurs probably because, both in social media and in printed and television newspapers, the amount of information on the scale of infection and deaths by Covid-19 was intense during this research. Believing in infection by the SARS-COV-2 can have a behavioral aspect of adherence to preventive measures to Covid-19; however, the strength of this belief can lead to a higher level of mental suffering. González-Sanguino et al. (2020) found tremendous mental anguish in people whose family members had Covid-19. In this present study, the greater the belief in the possibility of infection itself, the greater the level of depression. A greater certitude in the likelihood of a family member becoming contaminated predicted higher levels of depression and psychological stress and lower levels of life satisfaction. In this sense, the information may have acted as reinforcing stimuli, maintaining the perceived threat to survival, working as a prolonged emotional response to a dangerous situation (Brandão, 2017).

A higher level of education predicted less sadness and greater satisfaction with life. More time working at home and exercising each day predicted lower levels of depression. These last aspects portray the situation related to inequality in Brazil (Garrido \& Rodrigues, 2020). Those with higher education are more likely to be in jobs that enable remote work, generating feelings of more security when 
compared to those with less education or with fewer workloads, and consequently, lesser income, and from what we have seen, less mental suffering.

\section{Conclusion}

The Brazilian population is suffering mental distress during the pandemic. It is possible that some characteristics, mainly gender and socioeconomic status, explain the levels of psychological and emotional reactions and aid in outlining ways of prevention and treatment. Others, however, go beyond social classes and seem to affect all of us equally. Fearing for one's own life and family members is after all, fundamentally human. The Unified Mental Health System for an efficient public policy needs good predictors to plan its prevention and actions. To this end, it is necessary to implement public policies that contemplate the development of coping strategies so as to maintain the mental health of the Brazilian population in the current scenario, as well as in similar future situations. To minimize the pandemic's impacts on mental health, it is essential to provide different options for men and women, as well as for varying levels of education, and to consider the difference between people who have been infected and those who have not. The lack of control generated by the pandemic itself, which was aggravated by the circumstances in Brazil, leading to an increase in infection and casualties in the time period, shows a clear relationship to psychological suffering. From the results presented in this research, there is no single solution or "magic trick" capable of alleviating the psychological torment currently afflicting the population of Brazil. We can consider that the reliable results of scientific studies and research can positively influence Brazilians' physical health as well as mental health. An example would be the monitoring of mental health indicators in the Brazilian population.

\section{REFERENCES}

Abad, A., da Silva, J.A., de Paiva Teixeira, L.E.P., Antonelli-Ponti, M., Bastos, S., Mármora, C.H.C., Campos, L.A.M., Paiva, S., de Freitas, R.L. and da Silva, J.A. 2020. Evaluation of Fear and Peritraumatic Distress during COVID-19 Pandemic in Brazil. Advances in Infectious Diseases, 10, 184-194. https://doi.org/ 10.4236/aid.2020.103019

Antonelli-Ponti, M., Cardoso, F., Pinto, C. DaSilva, J. A. 2020. Efeitos da pandemia de COVID-19 no Brasil e em Portugal: estresse peritraumático. Revista Psicologia em Pesquisa 14 (4), 240-259. https://doi.org/10.34019/1982-1247.2020.v14.32262

Bedin, L. M. and Sarriera, J. C. 2014. Propriedades psicométricas das escalas de bem-estar: PWI, SWLS, BMSLSS e CAS. Avaliação Psicológica, 13(2), 213-225.

Brandão, M. L. 2017. As bases biológicas do comportamento. São Paulo: Editora Pedagógica Universitária.

Choi, E. P. H., Hui, B. P. H., and Wan, E. Y. F. 2020. Depression and anxiety in Hong Kong during COVID-19. International Journal of Environmental Research and Public Health, 17 (10), 3740. https://doi.org/10.3390/ijerph17103740

da Silva, J. A., \& Ribeiro-Filho, N. P. (2011). A dor como um problema psicofísico. Revista Dor, 12(2), 138-151. https://doi.org/10.1590/ S1806-00132011000200011
De Paiva Teixeira, L., Freitas, R., Abad, A., da Silva, J., Antonelli-Ponti, M., Bastos, S., Mármora, C., Campos, L., Paiva, S. and Da Silva, J. (2020) Psychological Impacts Related to Stress and Fear during the COVID-19 Pandemic: Cardiovascular Diseases, Diabetes, and Psychological Disorders as Risk Factors. World Journal of Neuroscience, 10, 191-205. https://doi.org/10.4236/wins.2020.104019

Diener E, Emmons RA, Larsen RJ, Griffin S. (1985). The Satisfaction With Life Scale. J Pers Assess. Feb; 49(1):71-5. https://doi.org/ 10.1207/s15327752jpa4901_13

Diener, E. 2012. New findings and future directions for subjective wellbeing research. American Psychologist, 67(8), 590-597. https://doi.org/10.1037/a0029541

Easton, S.D., Safadi, N.S., Wang, Y.et al. The Kessler psychological distress scale: translation and validation of an Arabic version. Health Qual Life Outcomes 15, 215 (2017). https://doi.org/10.1186/s12955017-0783-9

Garrido, R. G., \& Rodrigues, R. C. 2020. Restrição de contato social e saúde mental na pandemia: possíveis impactos das condicionantes sociais. Journal of Health \& Biological Sciences, 8(1), 1-9. http://dx.doi.org/10.12662/2317-3076jhbs.v8i1.3325.p1-9.2020

González-Sanguino, C., Ausín, B., Ángel Castellanos, M., Saiz, J., LópezGómez, A., Ugidos, C., and Muñoz, M. 2020. Mental health consequences during the initial stage of the 2020 Coronavirus pandemic (COVID-19) in Spain. Brain, Behavior, and Immunity. https://doi.org/10.1016/j.bbi.2020.05.040

Kang, L., Ma, S., Chen, M., Yang, J., Wang, Y., Li, R., ... \& Hu, S. 2020. Impact on mental health and perceptions of psychological care among medical and nursing staff in Wuhan during the 2019 novel coronavirus disease outbreak: A cross-sectional study. Brain, Behavior, and Immunity https://doi.org/10.1016/j.bbi.2020.03.028

Kessler R. C, Andrews G, Colpe LJ, Hiripi E, Mroczek DK, Normand SL, Walters EE, Zaslavsky AM. (2002a) Short screening scales to monitor population prevalences and trends in non-specific psychological distress. Psychol Med. Aug; 32(6):959-76. https://doi.org/10.1017/s0033291702006074

Kessler, R.C., Andrews, G., Colpe, et al 2002b. Short screening scales to monitor population prevalences and trends in non-specific psychological distress.Psychological Medicine, 32, 959-956. https://doi.org/10.1017/S0033291702006074

Lima, R. C. 2020. Distanciamento e isolamento sociais pela Covid-19 no Brasil: impactos na saúde mental. Physis: Revista de Saúde Coletiva, 30, e300214. https://doi.org/10.1590/S0103-7331202 0300214

Moccia, L., Janiri, D., Pepe, M., Dattoli, L., Molinaro, M., De Martin, V., and Di Nicola, M. 2020. Affective temperament, attachment style, and the psychological impact of the COVID-19 outbreak: an early report on the Italian general population. Brain, Behavior, and Immunity. https://doi.org/10.1016/j.bbi.2020.04.048

Taylor, S. 2019. The psychology of pandemics: Preparing for the next global outbreak of infectious disease. Cambridge Scholars Publishing.

Yamamoto, T., Uchiumi, C., Suzuki, N., Yoshimoto, J. and MurilloRodriguez, E. 2020. The psychological impact of mildlock down'in Japan during the COVID-19 pandemic: a nationwide survey under a declared state of emergency. Med Rxiv. https://doi.org/10.1101/2020.07.17.20156125

Yu, H., Li, M., Li, Z., Xiang, W., Yuan, Y., Liu, Y., ... \&Xiong, Z. 2020 Coping style, social support, and psychological distress in the general Chinese population in the early stages of the COVID-2019 epidemic. Social Support and Psychological Distress in the General Chinese Population in the Early Stages of the COVID-2019 Epidemic (3/13/2020). https://doi.org//10.2139/ssrn.3556633 